Journal of Nuclear Medicine, published on August 19, 2021 as doi:10.2967/jnumed.121.262324

\title{
Positron-emission tomography-based staging is cost-effective in early-stage follicular lymphoma
}

\section{Short running title:}

Cost-effectiveness of staging PET in follicular lymphoma

Andrea C. Lo ${ }^{1}$, Lyndon P. James ${ }^{2,3}$, Anca Prica ${ }^{4}$, Adam Raymakers ${ }^{5}$, Stuart Peacock ${ }^{5}$, Melody Qu' ${ }^{6}$ Alex V. Louie7, Kerry J. Savage ${ }^{8}$, Laurie H. Sehn ${ }^{8}$ David Hodgson9, Joanna C. Yang ${ }^{10}$, Hans T. T. Eich ${ }^{11}$, Andrew Wirth ${ }^{12}$, and M. G. Myriam Hunink ${ }^{3,13}$;

${ }^{1}$ Department of Radiation Oncology, BC Cancer, University of British Columbia, Vancouver, BC, Canada, 2PhD Program in Health Policy, Harvard University, Cambridge, MA, ${ }^{3}$ Center for Health Decision Science, Harvard T.H. Chan School of Public Health, Boston, MA, ${ }^{4}$ Department of Medical Oncology and Hematology, Princess Margaret Cancer Centre, Toronto, ON, Canada, ${ }^{5}$ Cancer Control Research, BC Cancer, Vancouver, BC, Canada, ${ }^{6}$ Department of Radiation Oncology, London Health Sciences Centre, Western University, London, ON, Canada, ${ }^{7}$ Department of Radiation Oncology, Sunnybrook Health Sciences Centre, University of Toronto, Toronto, ON, Canada, ${ }^{8}$ Centre for Lymphoid Cancer, Department of Medical

Oncology, BC Cancer, Vancouver, BC, Canada, ${ }^{9}$ Radiation Medicine Program, Princess Margaret Cancer Centre, Toronto, ON, Canada, ${ }^{10}$ Department of Radiation Oncology, University of California, San Francisco, San Francisco, CA, 11Department of Radiation Oncology, University Hospital Muenster, Muenster, Germany, ${ }^{12}$ Department of 
Radiation Oncology, Peter MacCallum Cancer Centre, Melbourne 8006, Australia, ${ }^{13}$ Clinical Epidemiology and Radiology, Erasmus University, Rotterdam, Netherlands.

\section{Corresponding and first author:}

Andrea C. Lo

Department of Radiation Oncology

BC Cancer

600 W. $10^{\text {th }}$ Avenue

Vancouver, British Columbia, V5Z 4E1, Canada

Phone: 604-877-6000, ext. 2672

Fax: 604-877-0505

Andrea.Lo@bccancer.bc.ca

Word count: 5874 words

Key words: PET/CT, follicular lymphoma, radiation therapy, cost-effectiveness analysis, staging 


\section{ABSTRACT}

Rationale: The objective was to assess the cost-effectiveness of staging positron emission tomography/computed tomography (PET/CT) in early-stage follicular lymphoma from the Canadian health care system perspective.

Methods: The study population was FL patients staged as early-stage using conventional CT imaging and planned for curative-intent radiation therapy (RT). A decision analytic model simulated the management after adding a staging PET/CT vs. using staging CT alone. In the no-PET/CT strategy, all patients proceeded to curative-intent RT as planned. In the PET/CT strategy, PET/CT information could result in an increased RT volume, switching to a non-curative approach, or no change in RT treatment as planned. Subsequent disease course was described using a state-transition cohort model over a 30-year time horizon. Diagnostic characteristics, probabilities, utilities and costs were derived from the literature. Baseline analysis was performed using quality-adjusted life years (QALYs), costs (2019 Canadian dollars, CAD\$) and the incremental cost-effectiveness ratio. Deterministic sensitivity analyses were conducted, evaluating net monetary benefit at a willingness-to-pay threshold of $\$ 100,000 /$ QALY. Probabilistic sensitivity analysis using 10,000 simulations was performed. Costs and QALYs were discounted at a rate of $1.5 \%$.

Results: In the reference case scenario, staging PET/CT was the dominant strategy, resulting in an average lifetime cost saving of \$3,165 and a gain of 0.32 QALYs. In deterministic sensitivity analyses, the PET/CT strategy remained the preferred strategy for all scenarios supported by available data. In probabilistic sensitivity 
analysis, the PET/CT strategy was strongly dominant in $77 \%$ of simulations (i.e., reduced cost and increased QALYs), and was cost-effective in $89 \%$ of simulations (i.e., either cost-saving or with an incremental cost-effectiveness ratio below $\$ 100,000 /$ QALY).

Conclusion: Our analysis shows that the use of PET/CT to stage early-stage FL patients reduces cost and improves QALYs. Patients with early-stage FL should undergo PET/CT prior to curative-intent RT.

\section{INTRODUCTION}

For patients with early-stage follicular lymphoma (FL), definitive radiation therapy (RT) is a potentially curative treatment, with a 10 -year event free survival of $40-50 \%(1-3)$. On the other hand, advanced-stage disease is considered incurable, but is still associated with a long median overall survival of 15-20 years (4), given its indolent nature and response to various treatments.

Since its introduction, computed tomography (CT) scan has been an integral part of lymphoma staging, allowing anatomic visualization of nodal and extranodal disease. In the current era, fluorodeoxyglucose (FDG)-positron emission tomography (PET) combined with CT in a single procedure (PET/CT) is considered state-of-the-art imaging in lymphoma $(3,5,6)$. A recent retrospective cohort study of early-stage FL patients staged with PET/CT suggested a modest improvement in intermediate-term outcomes when compared to conventionally staged early-stage FL cohorts $(7,8)$, and guidelines have been revised to recommend both staging CT 
and staging PET/CT to confirm localized disease or in the case of suspected transformation $(4,9)$. Nevertheless, not all centers have shifted to routinely utilizing PET/CT in the staging of FL patients $(3,5,6,10)$. Furthermore, neither the prior studies nor the recent guidelines considered the potential downstream impact of PET/CT staging on patient outcomes or the cost-effectiveness of adding functional imaging to CT alone.

A complete assessment of the impact of staging PET/CT requires the altered outcomes of the patients who are upstaged to be accounted for. Furthermore, evaluation of quality-adjusted life expectancy and cost-effectiveness facilitates comparison of staging PET/CT with other medical interventions for which these outcomes have been described. Thus, we sought to determine the impact of staging PET/CT on quality-adjusted life years (QALYs) and cost to the Canadian health care system in patients with early-stage FL planned for curative-intent RT.

\section{METHODS}

The population examined was patients with low-grade (grade 1-3A) FL staged as early-stage (stage I-II) using conventional CT imaging and planned for curative-intent radiation therapy (RT); the age of the base case patient was 60 years old. A decision analytic model was developed to simulate the management of patients after adding a staging PET/CT to the staging approach vs. using staging CT alone (see Figure 1). In the no-PET/CT strategy, all patients proceeded to curativeintent RT as planned. In the PET/CT strategy, PET/CT information could result in an 
increased RT volume, switching to a non-curative approach, or no change in treatment.

Patients' subsequent disease course was described using a state-transition cohort model over a 30-year lifetime horizon. A simplified version of the model is displayed in Figure 2. Patients upstaged to advanced-stage on PET/CT were managed with rituximab monotherapy, watchful waiting, palliative RT (4Gy in 2 fractions), or bendamustine-rituximab. Patients staged as early-stage received curative-intent RT (24Gy in 2 fractions). On relapse/progression, patients were treated with either bendamustine-rituximab plus rituximab maintenance if they hadn't previously received it, and salvage chemotherapy if they had. After bendamustine-rituximab, patients could receive up to 3 further lines of chemotherapy after which they transitioned into a palliative state and eventually death. Patients were assumed to still have indolent disease on relapse/progression rather than transformation to high-grade disease.

Direct medical costs from the Canadian health care system perspective were estimated from published literature and adjusted to 2019 CAD\$. Incremental costeffectiveness ratios (ICER) were calculated, and a willingness-to-pay (WTP) threshold of $\$ 100,000$ per QALY was adopted (11). QALYs and costs were discounted at an annual rate of $1.5 \%(12)$.

Various sensitivity analyses were performed to address model uncertainties and to establish the thresholds whereby each treatment strategy would be preferred. The baseline values and probability distributions are listed in Supplemental Tables 1 and 2. Deterministic one-way sensitivity analysis was 
performed to evaluate each variable's influence on the net monetary benefit at a WTP of $\$ 100,000 / Q A L Y$. Probabilistic sensitivity analysis was performed using 10,000 simulations, each using a parameter set drawn from the distributions described in Supplemental Tables 1 and 2. TreeAge Pro 2019 (TreeAge Software, Williamstown, MA, USA) was used to construct the model and perform the analyses.

\section{Transition Probabilities}

The probabilities used in the model are shown in Supplemental Table 1(3,1322). The diagnostic probabilities of PET/CT were derived from a study by Wirth et al. assessing the impact of PET/CT on early-stage FL (13). Based on Wirth's data (as described in the supplement), a uniform distribution ranging between $62 \%(8 / 13)$ and $92 \%(12 / 13)$ was used in sensitivity analysis to conservatively estimate the uncertainty of the probability of a new PET/CT finding of advanced-stage disease. Similarly, a uniform distribution ranging between $0 \%(0 / 6)$ and $100 \%(6 / 6)$ was selected for the probability of early-stage disease truly outside the planned RT field for those in whom this was diagnosed on PET/CT.

Probabilities reflecting disease course were derived from randomized controlled trials (RCTs) if available and cohort studies if no relevant RCTs had been published. Further details are found in the supplement $(14,15,19,20,23,24)$. The probability of death from other causes was the age-related mortality per 6-month cycle according to Statistics Canada life tables (22). 


\section{Utilities and Costs}

A utility value representing health-related quality of life was assigned to each health state based on published values (Supplemental Table 1(25-29)). Costs were considered from the perspective of the Canadian health care system and were adjusted to 2019 Canadian dollars with the Consumer Price Index (http://www.bankofcanada.ca). Based on Wirth et al. (13), we accounted for the additional cost of a biopsy in approximately $16 \%$ of patients who have new findings on PET/CT. The costs of PET/CT and core biopsy were based on the 2019 Ontario Schedule of Benefits for Physician Services. The cost of a 12-fraction course (27) of intensity-modulated radiation therapy was derived from a Canadian costing model (30). Further medical costs and their derivations are detailed in Supplemental Table $2(19,23,30-40)$

\section{RESULTS}

\section{Cost-Utility Analysis}

In the base-case scenario, PET/CT was the dominant strategy. The noPET/CT strategy resulted in 14.09 QALYs and a cost of $\$ 98,657$. The PET/CT strategy resulted in 14.40 QALYs at a cost of $\$ 95,491$, representing a gain of 0.32 QALYs and an average lifetime cost saving of $\$ 3,165$. 


\section{Sensitivity Analyses}

One-way sensitivity analyses were conducted for each variable, evaluating net monetary benefit at a willingness-to-pay threshold of \$100,000/QALY; a range of $0-100 \%$ was used for testing probabilities, $0-1$ for utilities, and $0-\$ 500,000$ for costs. As shown in supplemental figure 1, the no-PET/CT strategy became the preferred strategy only in scenarios that are not supported by available data, including when the probability of progression after rituximab monotherapy in advanced-stage disease was $>8.3 \%$ per 6 months, probability of progression after watchful waiting in advanced-stage disease was $<4 \%$ per 6 months, and utility of first remission was $<0.66$. The no-PET/CT strategy also became preferred when the proportion of advanced-stage patients requiring bendamustine-rituximab was $>48.0 \%$, receiving watchful waiting was $>89.3 \%$, and receiving palliative-intent RT was $>75.4 \%$. The model was robust to a very wide range of costs in one-way sensitivity analyses. The no-PET/CT strategy was only preferred when costs were unrealistically high: $>\$ 36,040$ for a PET $/ C T,>\$ 340,653$ for bendamustine-rituximab after rituximab monotherapy, and $>\$ 60,815$ for a follow-up appointment. The model was not sensitive to the costs of RT, biopsy, salvage chemotherapy, rituximab maintenance, biopsy, bendamustine-rituximab after RT or watchful waiting, medical oncology consultation, or palliation.

The net monetary benefit of the PET/CT strategy increased with increasing probabilities of PET/CT detecting advanced-stage disease (pAS) and PET/CT detecting early-stage disease outside planned RT field (pORT). PET/CT also remained the optimal strategy across the range of relevant values for both 
parameters in one-way sensitivity analyses. In two-way sensitivity analysis, the PET/CT strategy remained preferred unless $\mathrm{pAS}<1 \%$ and $\mathrm{pORT}<5 \%$ (see supplemental figure 3).

One-way sensitivity analyses were also performed on the probability of new findings on the PET/CT being correct. When advanced-stage disease is detected on PET/CT, the probability of a true positive only needs to be $>20.3 \%$ for the PET/CT strategy to be preferred. PET/CT remained the optimal strategy across the full range of probabilities of a true positive in the setting of PET/CT detecting early-stage disease beyond the planned RT volume.

\section{Probabilistic Sensitivity Analyses}

A probabilistic sensitivity analysis using 10,000 simulations was performed with the distributions described in Supplemental Tables 1 and 2. In $89.1 \%$ of simulations, the PET/CT strategy was cost-effective (i.e., either cost-saving and QALY-improving, or with an ICER below $\$ 100,000 /$ QALY) (see supplemental figure 2). In $77.1 \%$ of simulations, the PET/CT strategy was strongly dominant (i.e., reduced costs and increased QALYs).

\section{DISCUSSION}

Our analysis shows that adding PET/CT to the staging of early-stage FL patients reduces cost and improves QALYs. The existing literature on PET/CT in low-grade FL has focused on its diagnostic accuracy and impact on clinical 
management $(13,41-44)$. Although such analyses are important, they do not demonstrate the effect of PET/CT on clinical outcomes. Moreover, while outcomes of PET/CT staged early-stage FL have been reported $(7,8)$, the comparison with outcomes for conventionally staged early-stage FL does not reflect the true effect of staging PET/CT, given the exclusion of some patients after upstaging on PET/CT. Our decision analysis allows a more comprehensive evaluation of highly relevant endpoints, QALYs and cost-effectiveness. To our knowledge, this is the first costeffectiveness analysis (CEA) assessing the impact of PET/CT in early-stage FL.

While several studies demonstrate that PET/CT changed Ann Arbor staging in a significant proportion of patients with follicular lymphoma $(41,42,45)$, the vast majority of additional lesions detected by PET/CT have not been accompanied by subsequent biopsy and confirmation of lymphoma. A systematic review showed that only 3 of the 349 patients included across 7 studies had histological confirmation. While the false negative rate for PET/CT in early-stage FL is low $(42,43,46,47)$, the false-positive rate is uncertain and limited by a lack of systematic biopsies of relevant sites; thus, the implications of upstaging solely on the basis of PET/CT are unclear $(10,48)$. There were two parameters in our model that were related to the false vs. true positive rate of PET/CT, which were both tested in one-way sensitivity analyses: 1) the probability that a new PET/CT finding of advanced-stage disease is a true positive, and 2) the probability that a new PET/CT finding of early-stage disease outside the planned RT field is a true positive. When advanced-stage disease is detected on PET/CT, the PET/CT strategy is advantageous as long as the probability of a true positive is $>20 \%$; in other words, only if there is a high 
proportion $(>80 \%)$ of "false-positives" (i.e., patients whose PET/CT show advancedstage disease but truly have early-stage disease) leading to inappropriate treatment will the PET/CT strategy be detrimental. In the context of a new PET/CT finding of early-stage disease outside the planned RT field, the model is not sensitive to the true positivity rate; this is because inadvertently enlarging the RT field does not lead to a significant reduction in QALYs, given the low toxicity of RT (27). The uncertainty of PET/CT diagnostic accuracy was incorporated conservatively into the probabilistic sensitivity analysis using wide uniform distributions. Our model remained robust in deterministic and probabilistic sensitivity analyses, suggesting the PET/CT strategy is very likely to increase QALYs and reduce cost regardless of the exact value of the true positive rate.

The upstaging of FL by PET/CT has been investigated in a few studies, but to our knowledge, Wirth et al. is the only group that also reported the proportion of patients whose RT field was enlarged due to PET/CT findings (13). Thus, Wirth et al.'s study had the most complete data from which we derived our PET/CT-related transitional probabilities. However, given such scarce data on the probability of RT field enlargement, and the wide variation in the probability of upstaging across studies $(13,49-52)$, we tested these parameters in sensitivity analyses. As expected, the benefit of PET/CT decreased with decreasing proportion of new findings identified; however, the no-PET/CT strategy only became preferred if the probability of PET/CT detecting advanced-stage disease was $<0.09 \%$ and the probability of PET/CT detecting early-stage disease outside the planned RT was $<4 \%$, a scenario which is extremely unlikely. 
Of the patients upstaged to advanced-stage, a small proportion would have indications for chemoimmunotherapy, receiving bendamustine-rituximab according to our model, while the other patients are treated with rituximab monotherapy or watchful waiting. A large randomized controlled trial by Ardeshna et al. investigating upfront rituximab monotherapy vs. watchful waiting for asymptomatic stage II-IVA FL demonstrated significant improvements in progression-free survival and the time to initiation of the next treatment, with no overall survival benefit at a median follow-up of 4 years (18). Furthermore, a CEA comparing the two approaches showed that rituximab monotherapy increased life expectancy and QALYs over watchful waiting while being cost-saving (23), and the UK NICE guidelines recommend that rituximab monotherapy is offered to patients with asymptomatic advanced-stage FL (53). Despite the benefits of rituximab monotherapy, it is not universally used in asymptomatic advanced-stage FL; its utilization over watchful waiting and palliative-intent RT depends on factors such as physician practice and patient preference. Although the net monetary benefit of the PET/CT strategy decreases with increasing probability of watchful waiting $(\mathrm{pWW})$ or palliative-intent RT (pPRT), the PET/CT strategy was preferred as long as $\mathrm{pWW}<89 \%$ and $\mathrm{pPRT}<75 \%$. As our baseline pWW of $17.7 \%$ and pPRT of $5.6 \%$ were derived from a cohort predating randomized evidence on the benefit of rituximab monotherapy $(14,19)$, it is unlikely that pWW would approach $89 \%$ and pPRT would approach $75 \%$ in a given population. However, our model does suggest that the benefit of staging PET/CT over CT alone is smaller in a clinical practice where asymptomatic FL patients routinely undergo watchful waiting or palliative-intent RT; this is 
because a large driver of the benefit of staging PET/CT is the diversion of advancedstage patients to rituximab monotherapy, rather than RT (with no potential cure) followed by observation.

While our study population was defined as conventionally staged earlystage FL patients planned for curative-intent RT alone, it is worthwhile to consider the cost-effectiveness of staging PET/CT if alternative practices were employed for early-stage FL, such as RT plus adjuvant systemic therapy, systemic therapy alone, or watchful waiting. The main advantage of PET/CT is revealing disease that is not detected by CT alone, resulting in enlargement of the RT field, or a switch to systemic therapy or watchful waiting if the patient has advanced-stage disease; in a practice where all early-stage FL is treated with RT plus adjuvant systemic therapy, PET-CT would likely still be cost-effective, as the aforementioned benefits would still apply. In our current model, the main disadvantage of the "no PET/CT for staging" strategy is that some patients are treated inappropriately with curativeintent RT when in fact there is no curative potential; this disadvantage is likely exacerbated when an additional inappropriate treatment (i.e., R-CVP) is added, thereby, increasing the net benefit of the staging PET/CT strategy. In a practice where early-stage FL patients are treated with systemic therapy or watchful waiting, the upstaging from a PET/CT would likely result in more patients treated with systemic therapy than watchful waiting; given the superior PFS and costeffectiveness associated with rituximab induction over watchful waiting $(18,23)$, we suspect that staging PET/CT would remain cost-effective in this setting. On the other hand, in a practice where all early-stage FL patients are treated with systemic 
therapy or all are treated with watchful waiting, a staging PET/CT would not change management, and would be therefore unlikely to be cost-effective.

Several limitations to our model need to be considered. Autologous and allogeneic hematopoietic cell transplantation (HCT) were not included as salvage therapy. HCT is controversial $(54,55)$ and uncommonly used in FL, especially in a low-burden population like this one $(56,57)$, thus HCT would be unlikely to have a large impact on results. If HCT were to be included, it would lead to more conservative estimates, as HCT should preferentially increase expenditures in the no-PET/CT strategy because more people in this strategy would require salvage therapy due to fewer of them receiving potentially curative RT and fewer receiving rituximab monotherapy. Furthermore, salvage therapy options are rapidly evolving with varying practice patterns across centers which could affect costs; however, the model was extremely robust to costs for salvage therapy. As in many prior CEAs in FL (56,58-62), we did not account for the possibility of transformation to high-grade disease, which occurs at a cumulative incidence of approximately 1-2\% per year $(3,63,64)$. As this transformation risk applies to patients in both strategies, it is unlikely that incorporating it would significantly change the impact of staging PET/CT.

In conclusion, our study indicates that the addition of PET/CT for staging of early-stage FL patients planned for curative-intent RT reduces lifetime costs and improves patient QALYs. Patients with early-stage FL should therefore undergo PET/CT prior to curative-intent RT. While the costs of drugs and imaging studies are typically higher in the United States than in Canada, our model was not sensitive to 
any such cost until it far exceeded its true cost in either country. Therefore, while our analysis focuses on Canada, the results are relevant to international health care settings such as the United States, where clinical pathways are similar.

\section{DISCLOSURE STATEMENT}

S.P. is the Academic Representative Member of the Board of Directors for the Canadian Agency for Drugs and Technologies in Health. A.V.L. has received honoraria from AstraZenca, RefleXion and Varian Medical Systems. K.J.S. has received institutional research funding from Roche. L.H.S has consultancy and has received honoraria from Incyte, Gilead, Kite, Janssen, Celgene, Acerta, Genentech, Inc., AstraZeneca, Apobiologix, AbbVie, Amgen, Karyopharm, Lundbeck, Merck, MorphoSys, F. Hoffmann-La Roche Ltd, Seattle Genetics, Teva, Servier, Takeda, Chugai, TG therapeutics, and Verastem Oncology, and has received research funding

from Genentech, Inc., F. Hoffmann-LaRoche Ltd, and Teva. D.H. is the Medical Director of the Pediatric Oncology Group of Ontario. M.G.M.H. receives (or received) Royalties from Cambridge University Press for a textbook on Medical Decision Making, reimbursement of expenses from the European Society of Radiology (ESR) for work on the ESR guidelines for imaging referrals, reimbursement of expenses from the European Institute for Biomedical Imaging Research (EIBIR) for membership of the Scientific Advisory Board, and research funding from the American Diabetes Association, the Netherlands Organization for Health Research and Development, the German Innovation Fund, Netherlands Educational Grant 
("Studie Voorschot Middelen"), and the Gordon and Betty Moore Foundation. No other potential conflicts of interest relevant to this article exist.

\section{KEY POINTS}

Question: Is the addition of staging positron tomography/computed tomography (PET/CT) cost-effective in early-stage follicular lymphoma?

Pertinent Findings: A decision analytic and state-transition cohort model simulated patients' management and disease course after adding staging PET/CT vs. using conventional CT staging alone. Staging PET/CT was found to be the dominant strategy, resulting in both lifetime cost saving and gain in quality-adjusted life years. Implications for patient care: Patients with early-stage FL should undergo PET/CT prior to curative-intent radiation therapy. 


\section{REFERENCES}

1. Mac Manus MP, Hoppe RT. Is radiotherapy curative for stage I and II lowgrade follicular lymphoma? Results of a long-term follow-up study of patients treated at Stanford University. J Clin Oncol. 1996 Apr;14(4):1282-90.

2. Wilder RB, Jones D, Tucker SL, Fuller LM, Ha CS, McLaughlin P, et al. Longterm results with radiotherapy for Stage I-II follicular lymphomas. Int J Radiat Oncol Biol. 2001 Dec 1;51(5):1219-27.

3. Lo AC, Campbell BA, Pickles T, Aquino-Parsons C, Sehn LH, Connors JM, et al. Long-term outcomes for patients with limited-stage follicular lymphoma: update of a population-based study. Blood. 2020 Aug 20;136(8):1006-10.

4. Dreyling M, Ghielmini M, Rule S, Salles G, Vitolo U, Ladetto M, et al. Newly diagnosed and relapsed follicular lymphoma: ESMO Clinical Practice Guidelines for diagnosis, treatment and follow-up. Ann Oncol. Elsevier Masson SAS; 2016 Sep 1;27(Supplement 5):v83-v90.

5. König L, Herfarth K, Hörner-Rieber J, Dietrich S, Wiegel T, Jürgen D, et al. Oncological outcome and recurrence pattern analysis after involved-field irradiation in combination with rituximab for early-stage nodal and extranodal follicular lymphoma. Strahlenther Onkol. Springer Berlin Heidelberg; 2020 Jul 24;:1-10.

6. Pei S-N, Wang M-C, Ma M-C, Kuo C-Y, Liao C-K, Qiu H, et al. A comprehensive retrospective cohort study of the journey of B-cell lymphoma in Taiwan. Sci Rep. Nature Publishing Group UK; 2021 May 5;:1-12.

7. Brady JL, Binkley MS, Hajj C, Chelius M, Chau K, Balogh A, et al. Definitive radiotherapy for localized follicular lymphoma staged by 18F-FDG PET-CT: a collaborative study by ILROG. Blood. 2019 Jan 17;133(3):237-45.

8. Ng SP, Khor R, Bressel M, MacManus M, Seymour JF, Hicks RJ, et al. Outcome of patients with early-stage follicular lymphoma staged with 18F-

Fluorodeoxyglucose (FDG) positron emission tomography (PET) and treated with radiotherapy alone. Eur J Nucl Med Mol Imaging. Springer Berlin Heidelberg; 2019 Jan;46(1):80-6.

9. Cheson BD, Fisher RI, Barrington SF, Cavalli F, Schwartz LH, Zucca E, et al. Recommendations for Initial Evaluation, Staging, and Response Assessment of Hodgkin and Non-Hodgkin Lymphoma: The Lugano Classification. J Clin Oncol. 2014 Sep 20;32(27):3059-67.

10. Adams HJA, Nievelstein RAJ, Kwee TC. Systematic review on the additional value of 18F-fluoro-2-deoxy-D-glucose positron emission tomography in staging follicular lymphoma. J Comput Assist Tomogr. 2017 Jan;41(1):98-103. 
11. Neumann PJ, Cohen JT, Weinstein MC. Updating cost-effectiveness - the curious resilience of the $\$ 50,000$-per-QALY threshold. N Engl J Med. 2014 Aug 28;371(9):796-7.

12. Guidelines for the Economic Evaluation of Health Technologies: Canada. 2017 Mar pp. 1-76.

13. Wirth A, Foo M, Seymour JF, MacManus MP, Hicks RJ. Impact of [18F] Fluorodeoxyglucose Positron Emission Tomography on Staging and Management of Early-Stage Follicular Non-Hodgkin Lymphoma. International Journal of Radiation OncologyBiologyPhysics. 2008 May;71(1):213-9.

14. Friedberg JW, Taylor MD, Cerhan JR, Flowers CR, Dillon H, Farber CM, et al. Follicular lymphoma in the United States: first report of the National LymphoCare study. J Clin Oncol. 2009 Mar 10;27(8):1202-8.

15. Binkley MS, Brady JL, Hajj C, Chelius M, Chau K, MD AB, et al. Salvage treatment and survival for relapsed follicular lymphoma following primary radiation therapy: a collaborative study on behalf of ILROG. Int J Radiat Oncol Biol. Elsevier Inc; 2019 Jul 1;104(3):522-9.

16. Barzenje DA. Radiotherapy compared to other strategies in the treatment of stage I/II follicular lymphoma: a study of 404 patients with a median followpp of 15 years. PLoS ONE. 2015 Jun 25;:1-17.

17. Ardeshna KM, Smith P, Norton A, Hancock BW, Hoskin PJ, MacLennan KA, et al. Long-term effect of a watch and wait policy versus immediate systemic treatment for asymptomatic advanced-stage non-Hodgkin lymphoma: a randomised controlled trial. The Lancet. 2003 Aug;362(9383):516-22.

18. Ardeshna KM, Qian W, Smith P, Braganca N, Lowry L, Patrick P, et al. Rituximab versus a watch-and-wait approach in patients with advanced-stage, asymptomatic, non-bulky follicular lymphoma: an open-label randomised phase 3 trial. Lancet Oncol. Elsevier Ltd; 2014 Mar 24;15(4):424-35.

19. Rummel MJ, Niederle N, Maschmeyer G, Banat GA, Grünhagen von U, Losem C, et al. Bendamustine plus rituximab versus CHOP plus rituximab as first-line treatment for patients with indolent and mantle-cell lymphomas: an openlabel, multicentre, randomised, phase 3 non-inferiority trial. The Lancet. 2013 Apr;381(9873):1203-10.

20. van Oers MHJ, Van Glabbeke M, Giurgea L, Klasa R, Marcus RE, Wolf M, et al. Rituximab maintenance freatment of relapsed/resistant follicular nonHodgkin's lymphoma: long-term outcome of the EORTC 20981 phase III randomized intergroup study. J Clin Oncol. 2010 Jun 10;28(17):2853-8.

21. Salles G, Seymour JF, Offner F, Lopez-Guillermo A, Belada D, Xerri L, et al. 
Rituximab maintenance for 2 years in patients with high tumour burden follicular lymphoma responding to rituximab plus chemotherapy (PRIMA): a phase 3, randomised controlled trial. Lancet. Elsevier Ltd; 2011 Jan 1;377(9759):42-51.

22. Statistics Canada. Data tables in PDF and TXT format [Internet]. 2020 [cited 2020 Nov 18]. pp. 1-1. Available from: https://www150.statcan.gc.ca/n1/pub/84-537- x/4064441-eng.htm

23. Prica A, Chan K, Cheung M. Frontline rituximab monotherapy induction versus a watch and wait approach for asymptomatic advanced-stage follicular lymphoma: A cost-effectiveness analysis. Cancer. 2015 Apr 15;121(15):263745.

24. Barzenje DA, Cvancarova Småstuen M, Liestøl K, Fossa A, Delabie J, Kolstad A, et al. Radiotherapy Compared to Other Strategies in the Treatment of Stage I/II Follicular Lymphoma: A Study of 404 Patients with a Median Follow-Up of 15 Years. Katoh M, editor. PLoS ONE. Public Library of Science; 2015;10(7):e0131158.

25. Wang H, Smith A, Yu G, Aas E, Bagguley T, Howell D, et al. UK utility elicitation in patients with follicular lymphoma. Value Health. 2017 Oct;20(9):A449-5.

26. Wild D, Walker M, Pettengell R, Lewis G. PCN62 Utility elicitation of patients with follicular lymphoma. Value Health. 2006 Nov;9(6):A294-1.

27. Hoskin PJ, Kirkwood AA, Popova B, Smith P, Robinson M, Gallop-Evans E, et al. 4 Gy versus 24 Gy radiotherapy for patients with indolent lymphoma (FORT): a randomised phase 3 non-inferiority trial. Lancet Oncol. Elsevier Ltd; 2014 Mar 24;15(4):457-63.

28. Wang H-I, Roman E, Crouch S, Aas E, Burton C, Patmore R, et al. A generic model for follicular lymphoma: predicting cost, life expectancy, and qualityadjusted-life-year using UK population-based observational data. Elsevier Inc; 2018 Oct 9;:1-10.

29. Fagnoni P, Milpied N, Limat S, Deconinck E. Cost effectiveness of high-dose chemotherapy with autologous stem cell support as initial treatment of aggressive non-Hodgkin's lymphoma. Pharmacoeconomics. 2009 Aug 16;27(1):55-68.

30. Yong JHE, McGowan T, Redmond-Misner R, Beca J, Warde P, Gutierrez E, et al. Estimating the costs of intensity-modulated and 3-dimensional conformal radiotherapy in Ontario. Curr Oncol. 2016 Jun 13;23(3):228-12.

31. Adams SJ, Rakheja R, Bryce R, Babyn PS. Incidence and economic impact of incidental findings on 18F-FDG PET/CT imaging. Can Assoc Radiol J. 2018 
Feb;69(1):63-70.

32. Ontario Ministry of Health and Long-Term Care. Schedule of benefits for physician services under the Health Insurance Act [Internet]. 2020 [cited 2020 Nov 17]. pp. 1-1. Available from:

http://www.health.gov.on.ca/en/pro/programs/ohip/sob/physserv/sob_ma ster20200 306.pdf

33. Mittmann N. Economic analysis of alemtuzumab (MabCampath $®)$ in fludarabinerefractory chronic lymphocytic leukemia. TOPHARMEJ. $2012 \mathrm{Apr}$ 6;4(1):18-25.

34. Cancer Care Ontario. Drug formulary. [Internet]. 2020 [cited 2020 Nov 16]. pp. 1-1. Available from:

https://www.cancercareontario.ca/en/drugformulary/drugs/riTUXimab.

35. Ontario Case Costing Initiative [Internet]. 2020 [cited 2020 Nov 16]. pp. 1-1. Available from: https://hsim.health.gov.on.ca/hdbportal/occi

36. Ontario Ministry of Health and Long-Term Care Schedule of benefits for laboratory services.docx [Internet]. 2020 [cited 2020 Nov 17]. pp. 1-1. Available from:

http://www.health.gov.on.ca/en/pro/programs/ohip/sob/lab/lab_mn2020.p df

37. Lathia N, Mittmann N, DeAngelis C, Knowles S, Cheung M, Piliotis E, et al. Evaluation of direct medical costs of hospitalization for febrile neutropenia. Cancer. 2010 Feb 1;116(3):742-8.

38. Pan-Canadian Oncology Drug Review. Final economic guidance report: bendamustine (Treanda) for non-Hodgkin lymphoma. [Internet]. 2020 [cited 2020 Nov 16]. pp. 1-9. Available from: https://cadth.ca/treanda-indolentnon-hodgkin-lymphoma

39. Herold M, Sacchi S, Hieke K. The cost of treating relapsed indolent nonHodgkin's lymphoma in an international setting: retrospective analysis of resource use. Haematologica. 2002 Jun 27;87:719-29.

40. Dumont S, Jacobs P, Fassbender K, Anderson D, Turcotte V, Harel F. Costs associated with resource utilization during the palliative phase of care: a Canadian perspective. Palliat Med. 3rd ed. 2009 Oct;23(8):708-17.

41. Metser U, Dudebout J, Baetz T, Hodgson DC, Langer DL, MacCrostie P, et al. [ 18F]-FDG PET/CT in the staging and management of indolent lymphoma: A prospective multicenter PET registry study. Cancer. 4 ed. 2017 Mar 13;123(15):2860-6. 
42. Fueger BJ, Yeom K, Czernin J, Sayre JW, Phelps ME, Allen-Auerbach MS. Comparison of CT, PET, and PET/CT for staging of patients with indolent nonHodgkin's lymphoma. Mol Imaging Biol. 2009 Mar 27;11(4):269-74.

43. Tsukamoto N, Kojima M, Hasegawa M, Oriuchi N, Matsushima T, Yokohama A, et al. The usefulness of 18F-fluorodeoxyglucose positron emission tomography (18F-FDG-PET) and a comparison of18F-FDG-pet with 67gallium scintigraphy in the evaluation of lymphoma. Cancer. 2007;110(3):652-9.

44. Ng SP, Khor R, Bressel M, MacManus M, Seymour JF, Hicks RJ, et al. Outcome of patients with early-stage follicular lymphoma staged with $18 \mathrm{~F}$ -

Fluorodeoxyglucose (FDG) positron emission tomography (PET) and treated with radiotherapy alone. Eur J Nucl Med. European Journal of Nuclear Medicine and Molecular Imaging; 2018 Nov 14;:1-7.

45. Adams HJA, Nievelstein RAJ, Kwee TC. Systematic review on the additional value of 18F-fluoro-2-deoxy-D-glucose positron emission tomography in staging follicular lymphoma. J Comput Assist Tomogr. 2017 Jan;41(1):98-103.

46. Elstrom R, Guan L, Baker G, Nakhoda K, Vergilio J-A, Zhuang H, et al. Utility of FDG-PET scanning in lymphoma by WHO classification. Blood. 2003 May 15;101(10):3875-6.

47. Wöhrer S, Jaeger U, Kletter K, Becherer A, Hauswirth A, Turetschek K, et al. 18F-fluoro-deoxy-glucose positron emission tomography (18F-FDG-PET) visualizes follicular lymphoma irrespective of grading. Ann Oncol. 2006 May;17(5):780-4.

48. McNamara C, Davies J, Dyer M, Hoskin P, Illidge T, Lyttelton M, et al. Guidelines on the investigation and management of follicular lymphoma. $\mathrm{Br} \mathrm{J}$ Haematol. 2011 Dec 23;156(4):446-67.

49. Le Dortz L, De Guibert S, Bayat S, Devillers A, Houot R, Rolland Y, et al. Diagnostic and prognostic impact of 18F-FDG PET/CT in follicular lymphoma. Eur J Nucl Med Mol Imaging. 2010 Aug 18;37(12):2307-14.

50. Luminari S, Biasoli I, Arcaini L, Versari A, Rusconi C, Merli F, et al. The use of FDG-PET in the initial staging of 142 patients with follicular lymphoma: a retrospective study from the FOLL05 randomized trial of the Fondazione Italiana Linfomi. Ann Oncol. 2013 Aug;24(8):2108-12.

51. Janikova A, Bolcak K, Pavlik T, Mayer J, Král Z. Value of [18F]fluorodeoxyglucose positron emission tomography in the management of follicular lymphoma: the end of a dilemma? Clin Lymphoma \& Myeloma. Elsevier Inc; 2011 Aug 5;8(5):287-93.

52. Ngeow JYY, Quek RHH, Ng DCE, Hee SW, Tao M, Lim LC, et al. High SUV uptake 
on FDG-PET/CT predicts for an aggressive B-cell lymphoma in a prospective study of primary FDG-PET/CT staging in lymphoma. Ann Oncol. 2009 Sep;20(9):1543-7.

53. NICE guideline NG52. Non-Hodgkin's lymphoma: diagnosis and management. National INstitute for Health and Care Excellence, 2016. [Internet]. 2020 [cited 2020 Nov 17]. pp. 1-1. Available from: https://www.nice.org.uk/guidance/ng52

54. Freedman A. Follicular lymphoma: 2018 update on diagnosis and management. Am J Hematol. 2018 Jan 8;93(2):296-305.

55. Montoto S, Corradini P, Dreyling M, Ghielmini M, Kimby E, Lopez-Guillermo A, et al. Indications for hematopoietic stem cell transplantation in patients with follicular lymphoma: a consensus project of the EBMT-Lymphoma Working Party. Haematologica. 2013 Jun 30;98(7):1014-21.

56. Hayslip JW, Simpson KN. Cost-effectiveness of extended adjuvant rituximab for US patients aged 65-70 Years with follicular lymphoma in second remission. Clin Lymphoma \& Myeloma. Elsevier Inc; 2008 Aug 3;8(3):166-70.

57. van Agthoven M, Kramer MHH, Sonneveld P, van der Hem KG, Huijgens PC, Wijermans PW, et al. Cost analysis of common treatment options for indolent follicular non-Hodgkin's lymphoma. Haematologica. 2005 Oct;90(10):142232.

58. Kasteng F, Erlanson M, Hagberg H, Kimby E, Relander T, Lundkvist J. Costeffectiveness of maintenance rituximab treatment after second line therapy in patients with follicular lymphoma in Sweden. Acta Oncol. 2009 Jul 8;47(6):1029-36.

59. Ray JA, Carr E, Lewis G, Marcus R. An evaluation of the cost-effectiveness of rituximab in combination with chemotherapy for the first-line treatment of follicular non-Hodgkin's lymphoma in the UK. Value Health. International Society for Pharmacoeconomics and Outcomes Research (ISPOR); 2010 Oct $6 ;: 1-12$.

60. Deconinck E, Miadi-Fargier H, Le Pen C, Brice P. Cost effectiveness of rituximab maintenance therapy in follicular lymphoma. Pharmacoeconomics. 2009 Dec 14;:1-13.

61. Soini EJ, Martikainen JA, Vihervaara V, Mustonen K, Nousiainen T. Economic evaluation of sequential treatments for follicular non-Hodgkin lymphoma. Clin Ther. Elsevier Inc; 2012 Apr 1;34(4):915-925.e2.

62. Chen Q, Ayer T, Nastoupil LJ, Rose AC, Flowers CR. Comparing the costeffectiveness of rituximab maintenance and radioimmunotherapy 
consolidation versus observation following first-line therapy in patients with follicular lymphoma. Value Health. Elsevier; 2015 Mar 1;18(2):189-97.

63. Montoto S, Davies AJ, Matthews J, Calaminici M, Norton AJ, Amess J, et al. Risk and clinical implications of transformation of follicular lymphoma to diffuse large B-cell lymphoma. J Clin Oncol. 2007 Jun 10;25(17):2426-33.

64. Federico M, Dolores Camallero Barringón M, Marcheselli L, Tarantino V, Manni M, MD CS, et al. Rituximab and the risk of transformation of follicular lymphoma: a retrospective pooled analysis. Lancet Haematol. Elsevier Ltd; 2018 Jul 23;5(8):e359-67. 
Figure 1. Decision tree depicting management after staging PET/CT vs. no staging PET/CT (M - State-transition cohort model; PET/CT - positron emission

tomography/computed tomography; RT - radiation therapy)

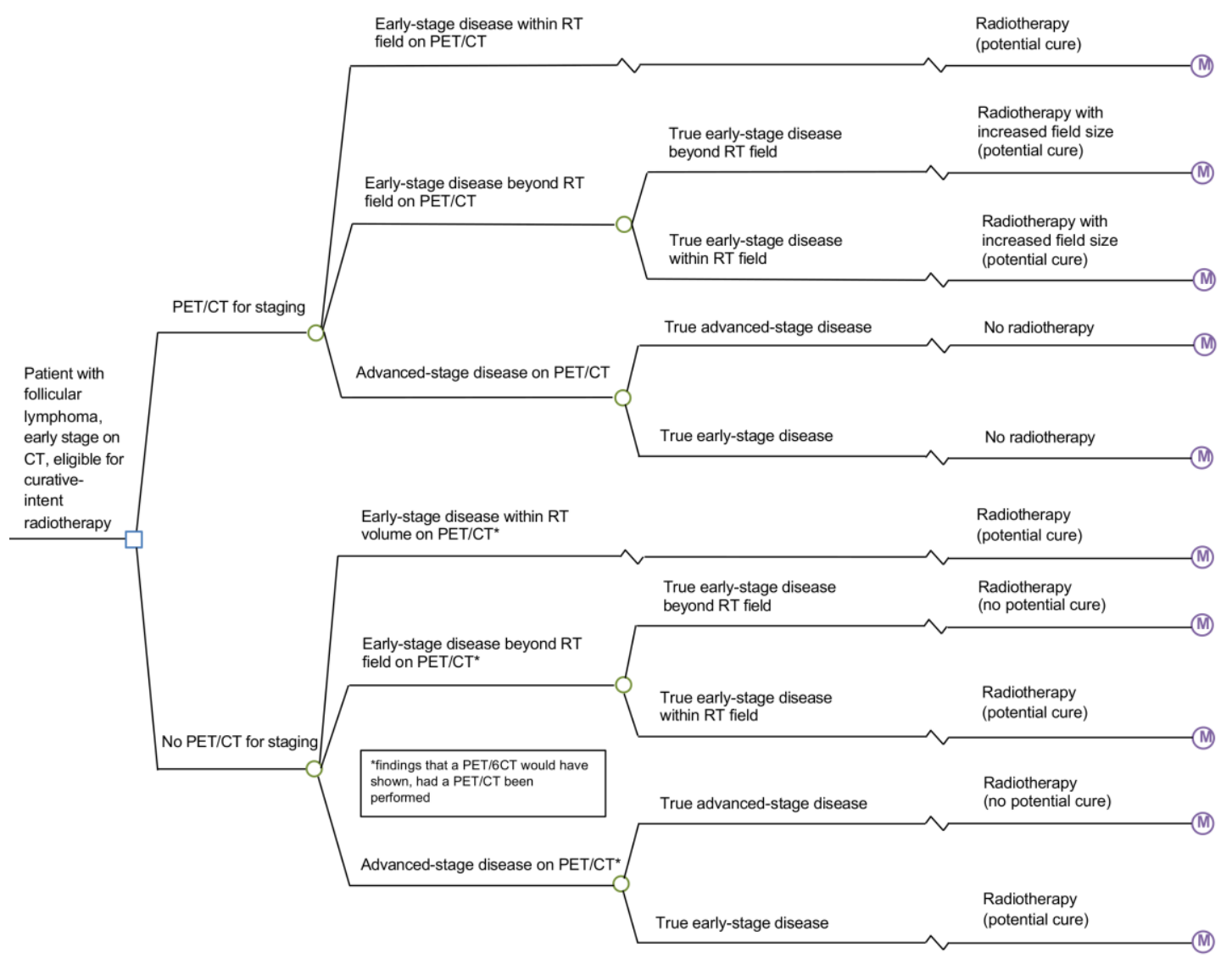


Figure 2. Simplified state-transition cohort model (dotted arrows represent

transition to next state after relapse/progression; solid arrows represent transition to next state without relapse/progression; RT - radiation therapy; PET/CT positron emission tomography/computed tomography)

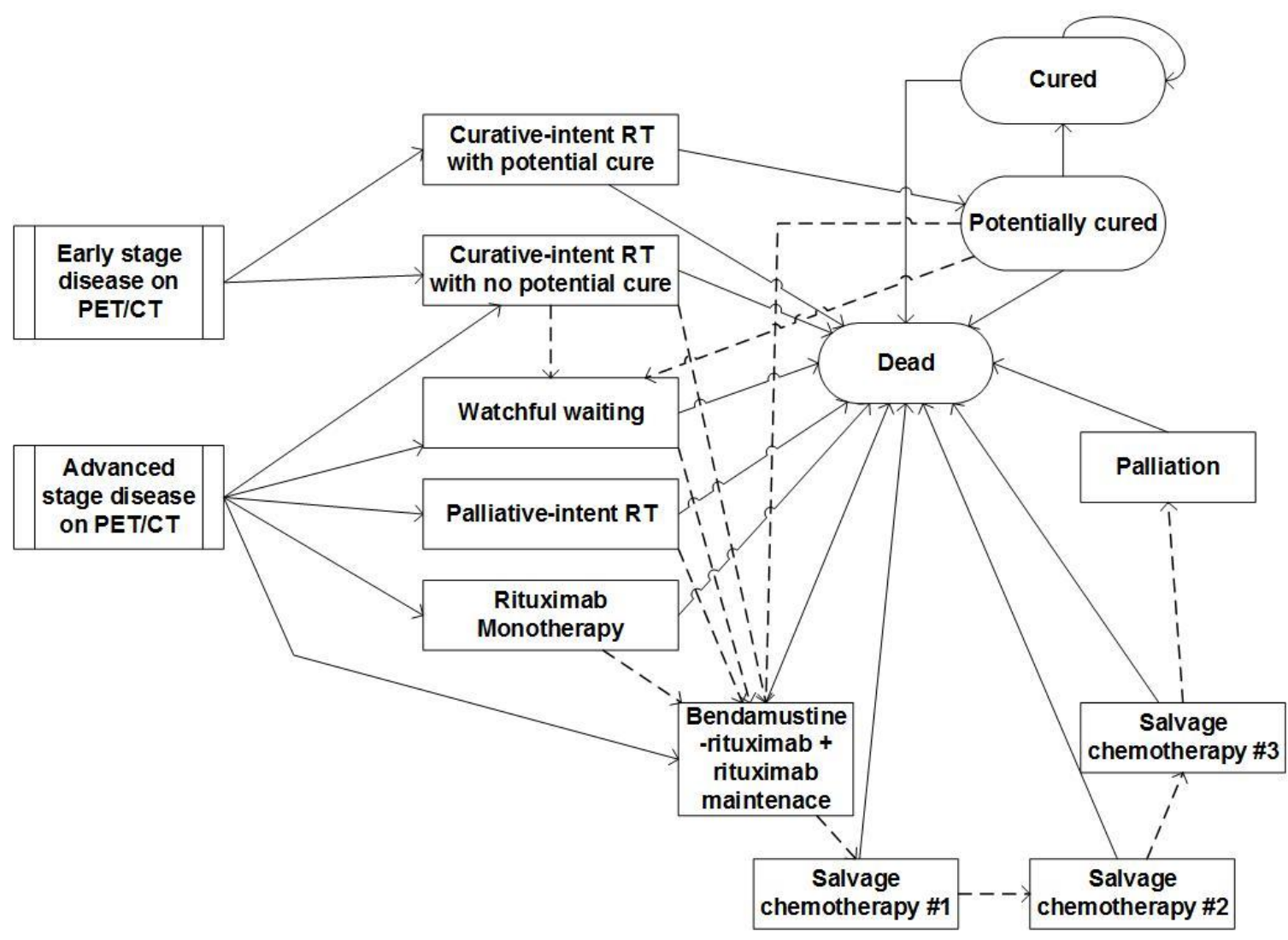


Graphical Abstract

\section{Incremental Cost-Effectiveness, PET/CT for staging vs. No PET/CT for staging}

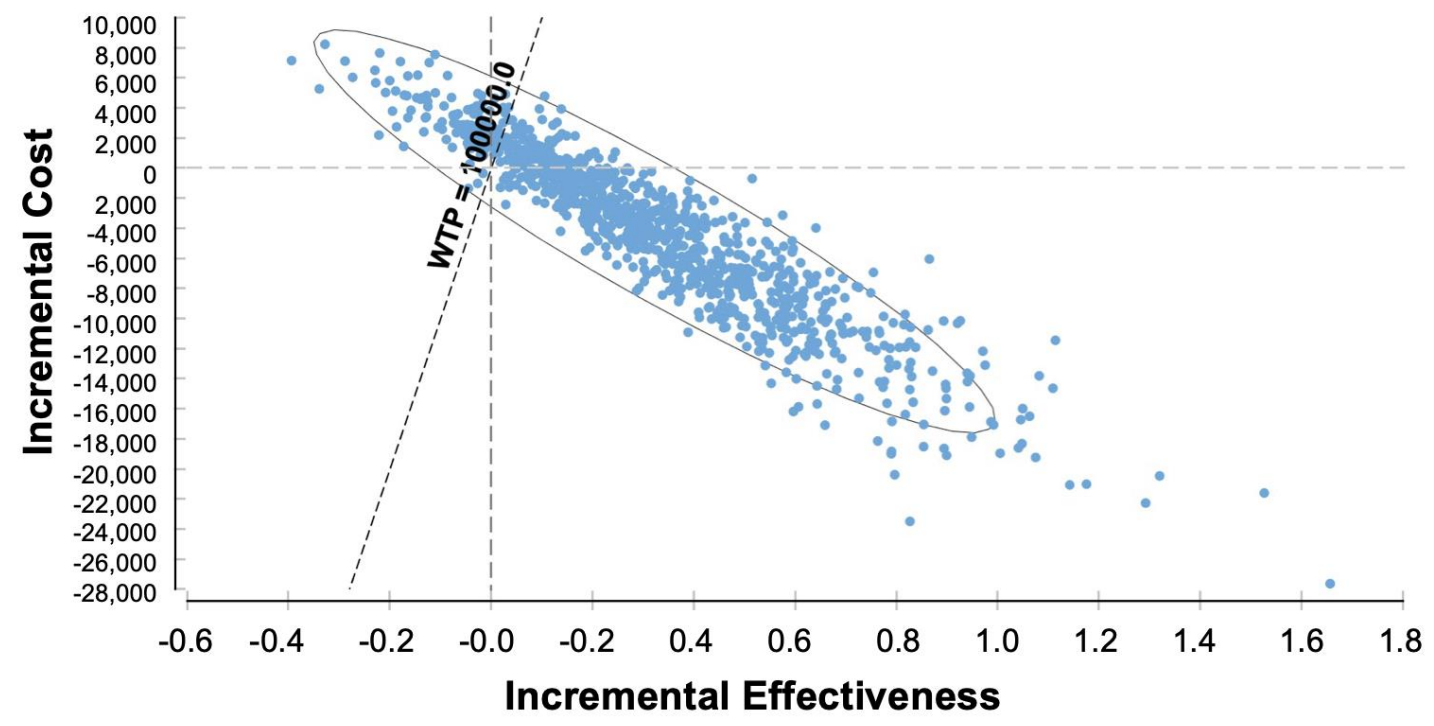




\section{SUPPLEMENT}

\section{Expanded Methods}

\section{Transition probabilities}

The probabilities used in the model are shown in Supplemental Table 1. The diagnostic probabilities of PET/CT were derived from a study by Wirth et al. assessing the impact of PET/CT on early-stage FL (13). In this study, 42 patients were found to have early-stage FL on conventional CT and subsequently had a staging PET/CT; based on this PET/CT, 13 (31\%) patients were upstaged to advanced-stage disease, 6 (14\%) remained classified as early-stage disease but required enlargement of the RT field to encompass findings that were not seen on the conventional CT, and 23 (55\%) had no new findings. Of the 13 patients who were upstaged to advanced-stage, 8 (62\%) were confirmed to be true positives either by biopsy $(\mathrm{N}=3)$, subsequent disease failure that was consistent with the PET abnormalities $(\mathrm{N}=3)$, or retrospective identification of missed abnormalities on $\mathrm{CT}$ $(\mathrm{N}=2)$; one $(8 \%)$ had an apparent false positive with bilateral symmetrical uptake in hilar lymph nodes that was later found to be reactive rather than malignant; and the other $5(36 \%)$ had no confirmation. Thus, to conservatively estimate the uncertainty of the probability of a new PET/CT finding of advanced-stage disease, a uniform distribution ranging between $62 \%(8 / 13)$ and $92 \%(12 / 13)$ was used in sensitivity analysis. Of the 6 patients whose RT fields required enlargement, none of them had a biopsy or other means to confirm whether these additional suspicious findings were true disease involvement (13). Similarly, a uniform distribution ranging between $0 \%(0 / 6)$ and $100 \%(6 / 6)$ was selected for the probability of early-stage disease truly outside the planned RT field for those in whom this was diagnosed on PET/CT.

Probabilities reflecting disease course were derived from randomized controlled trials (RCTs) if available and cohort studies if no relevant RCTs had been published. The overall response rate to bendamustine-rituximab was $93 \%$ according to a RCT by Rummel et al (19). A lower response rate to bendamustinerituximab of $88 \%$ was modeled in individuals who received rituximab monotherapy (23). The probability of progression after bendamustine-rituximab according to Rummel et al.'s trial was $6.8 \%$ per 6-month cycle, but the trial was performed without rituximab maintenance; on the basis of the PRIMA trial, the progression probability of Rummel et al.'s study was adjusted by the hazard ratio for progression on rituximab maintenance versus watchful waiting (hazard ratio, 0.60). Since a progression-free survival benefit from maintenance therapy might not be similarly preserved after bendamustine-rituximab (which has not been tested in clinical trials), this possibility was explored in sensitivity analyses. The response rate after second-line therapy (i.e., salvage chemotherapy \#1) was $85 \%$ based on a study by van Oers et al (20). A $20 \%$ penalty was applied to the response rate with each subsequent line of salvage chemotherapy, which was explored in sensitivity 
analyses. The probability of progression after salvage chemotherapy \#1, \#2 and \#3 were assumed to be constant (23).

The baseline estimates of advanced-stage patients managed with watchful waiting and radiotherapy were $17.7 \%$ and 5.6\%, based on the National LymphoCare Study, a multicenter, longitudinal observational study of 2,728 patients with FL (14). Of advanced-stage patients receiving treatment, the baseline estimate of patients requiring bendamustine-rituximab was 3.0\%, derived from the proportion of patients in a population-based CT-staged early-stage FL cohort (3) meeting criteria for first-line bendamustine-rituximab per Rummel et al.'s trial (19). The remaining advanced-stage patients were treated with rituximab monotherapy. The probabilities of advanced-stage patients being managed upfront with watchful waiting vs. bendamustine-rituximab vs. rituximab monotherapy were explored in sensitivity analyses.

Of early-stage patients who relapse after potentially curative RT, the proportion of patients treated with bendamustine-rituximab was based on a multicenter retrospective study showing that $24 \%$ of patients in this setting had systemic therapy (15); this estimate was explored in sensitivity analysis. For earlystage patients who did not receive potentially curative RT, rate of relapse requiring bendamustine-rituximab was $2.9 \%$ per 6-month cycle, derived from a large population-based study by Barzenje et al (16).

\section{Utilities and Costs}

Drug acquisition costs for rituximab and bendamustine were determined from Canadian cost analyses $(33,38)$. Supportive drug costs were obtained from hospital pharmacies. Pharmacy and nursing costs were obtained from hospital human resources departments. Resource utilization and overhead costs were extracted from published guidelines and statistics (33-35). Cost of medical visits, laboratory and imaging investigations were derived from the 2019 Ontario schedules of benefits for physician and laboratory services $(32,36)$. The costs associated with adverse events were derived from the literature and incorporated into the total systemic therapy costs (37).

The cost of salvage chemotherapy was derived from a cost analysis by Herold et al (39). The cost of 6 cycles of rituximab was added only to the first course of salvage chemotherapy since patients would likely not receive rituximab with subsequent chemotherapy lines. The cost of palliation per 6 months was based on a Canadian costing study (40). 


\section{Figures}

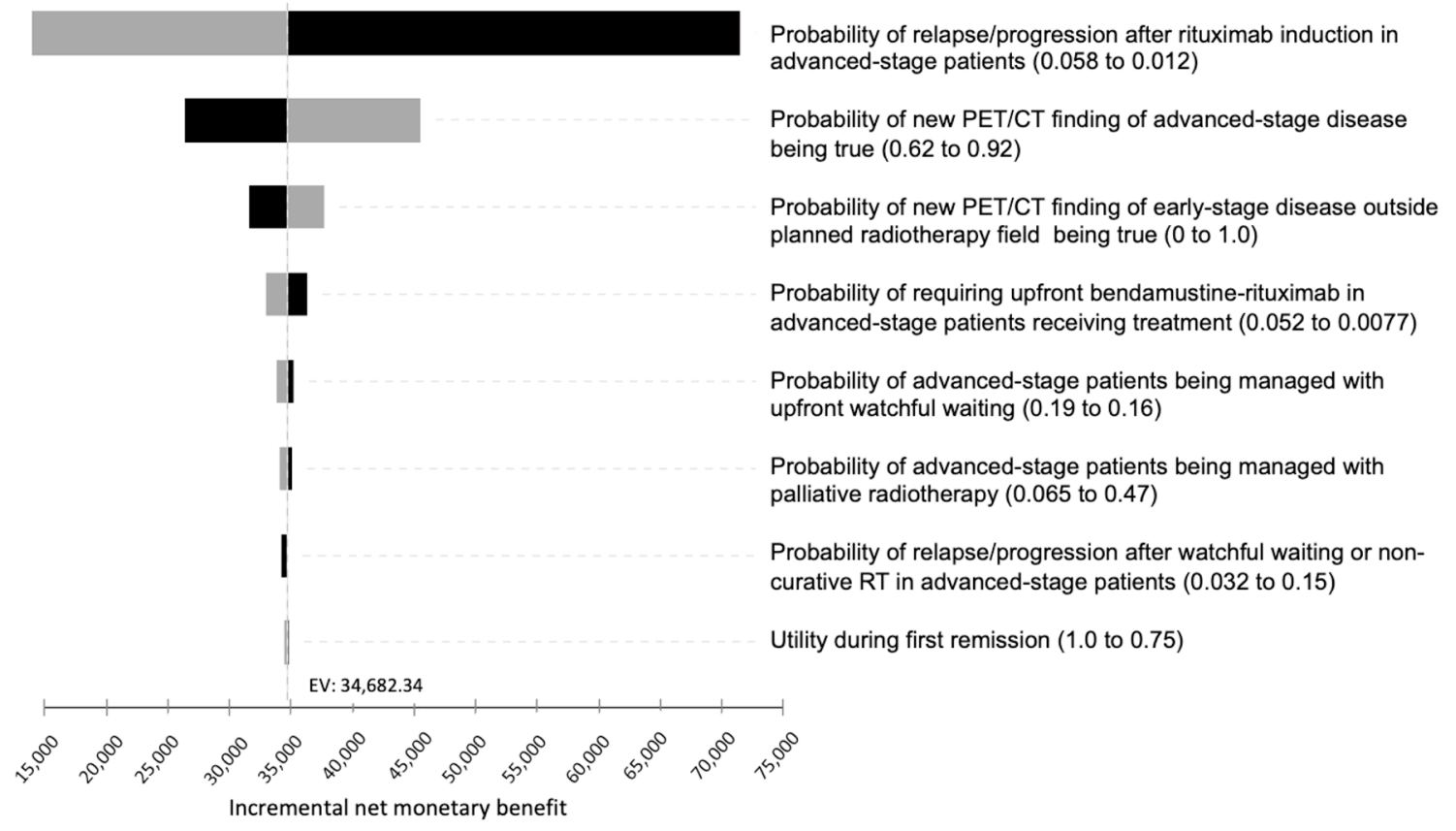

Supplemental Figure 1. Tornado diagram of incremental net monetary benefit (NMB) for PET/CT relative to the no-PET/CT strategy with a willingness-to-pay of $\$ 100,000 /$ QALY. A positive incremental NMB means that PET/CT is the preferred strategy, while a negative value would mean no-PET/CT is preferred. For all parameters, we see that PET/CT is preferred across the full range of values. The gray shade depicts the higher end of stated range and the black shade depicts the lower end of the stated range. 


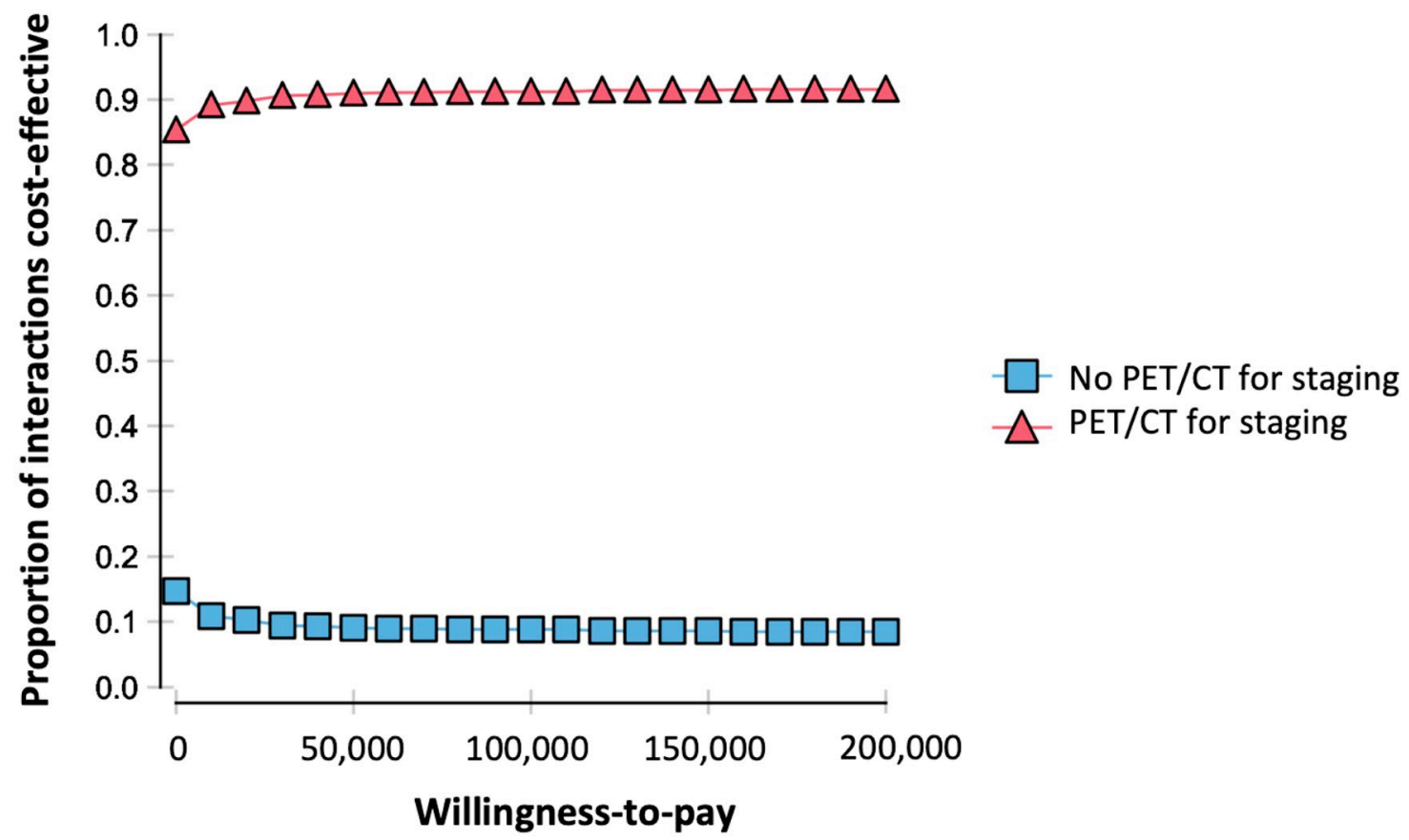

Supplemental Figure 2. Cost-effectiveness acceptability curve, showing the proportion of simulations from the probabilistic sensitivity analysis in which each strategy was the cost-effective strategy, at different willingness-to-pay thresholds. This can be interpreted as the probability that each strategy is cost-effective

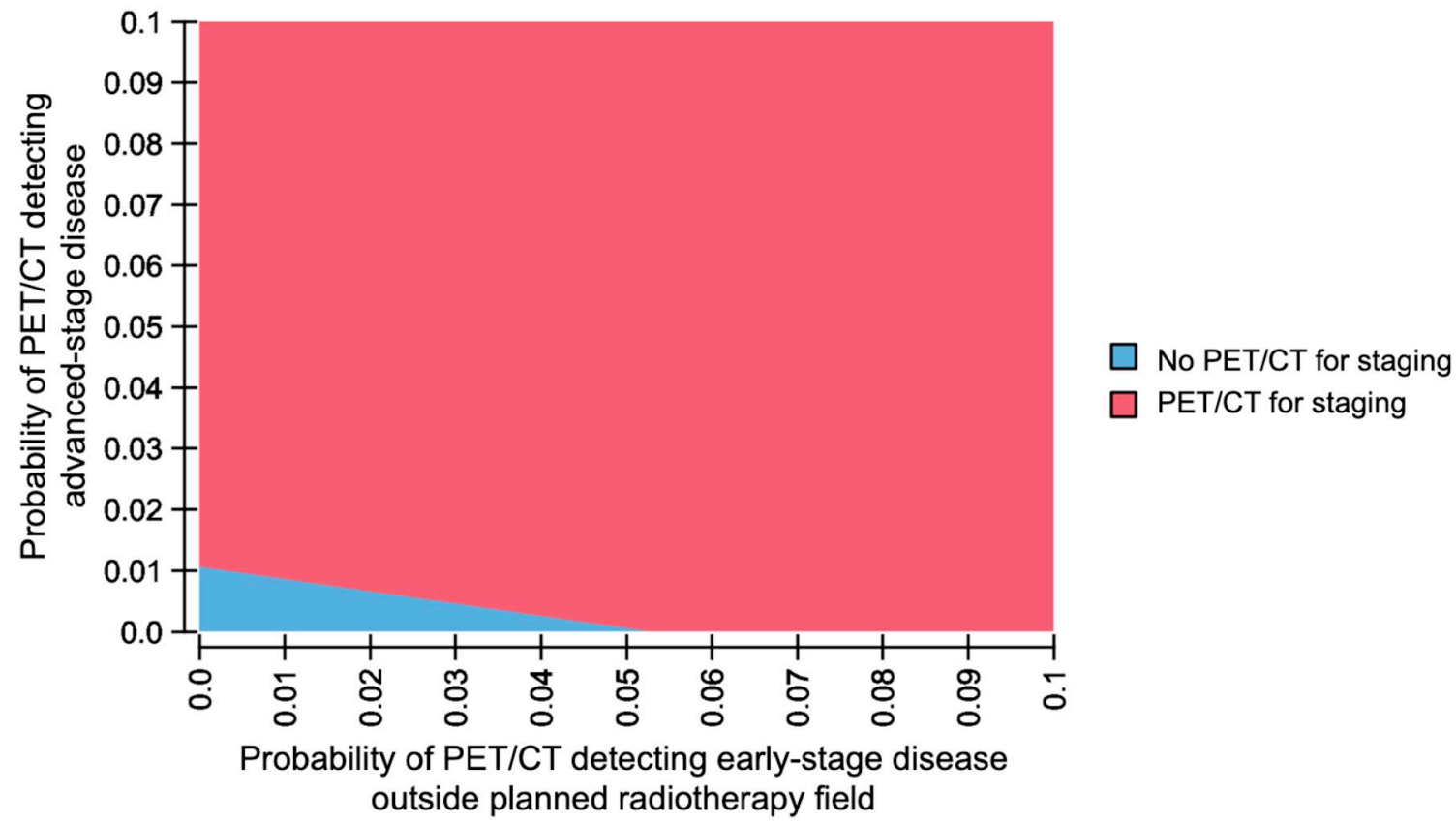

Supplemental Figure 3. Two-way sensitivity analysis on probabilities of PET/CT detecting new findings, evaluating net monetary benefit at a willingness-to-pay threshold of $\$ 100,000 /$ QALY 


\section{Tables}

Supplemental Table 1. Model parameters: probabilities and utilities normalized to a 6month period

\begin{tabular}{|c|c|c|c|c|}
\hline Parameter & Mean & $\begin{array}{l}\text { Standard } \\
\text { deviation }\end{array}$ & Distribution & References \\
\hline \multicolumn{5}{|l|}{ Diagnostic probabilities } \\
\hline $\begin{array}{l}\text { Probability of PET/CT having } \\
\text { no impact on planned RT }\end{array}$ & 0.55 & 0.076 & Beta & (13) \\
\hline $\begin{array}{l}\text { Probability of PET/CT } \\
\text { detecting early-stage disease } \\
\text { outside planned RT field }\end{array}$ & 0.14 & 0.053 & Beta & (13) \\
\hline $\begin{array}{l}\text { Probability of PET/CT } \\
\text { detecting advanced-stage } \\
\text { disease }\end{array}$ & 0.31 & 0.070 & Beta & (13) \\
\hline $\begin{array}{l}\text { Probability of new PET/CT } \\
\text { finding of early-stage disease } \\
\text { outside planned RT field } \\
\text { being a true positive }\end{array}$ & \multicolumn{2}{|c|}{$\begin{array}{l}\text { Minimum: } 0 \\
\text { Maximum: } 1.0\end{array}$} & Uniform & (13) \\
\hline $\begin{array}{l}\text { Probability of new PET/CT } \\
\text { finding of advanced-stage } \\
\text { disease being a true positive }\end{array}$ & \multicolumn{2}{|c|}{$\begin{array}{l}\text { Minimum: } 0.62 \\
\text { Maximum: } 0.92\end{array}$} & Uniform & (13) \\
\hline \multicolumn{5}{|l|}{$\begin{array}{l}\text { Disease course } \\
\text { probabilities }\end{array}$} \\
\hline $\begin{array}{l}\text { Probability of advanced-stage } \\
\text { patients being managed with } \\
\text { upfront watchful waiting }\end{array}$ & 0.18 & 0.0073 & Beta & $(14)$ \\
\hline $\begin{array}{l}\text { Probability of advanced-stage } \\
\text { patients being managed with } \\
\text { palliative-intent RT }\end{array}$ & 0.056 & 0.0045 & Beta & $(14)$ \\
\hline $\begin{array}{l}\text { Probability of requiring } \\
\text { upfront bendamustine- } \\
\text { rituximab in advanced-stage } \\
\text { patients receiving treatment }\end{array}$ & 0.030 & 0.011 & Beta & (3) \\
\hline $\begin{array}{l}\text { Probability of relapse after } \\
\text { potentially curative RT }\end{array}$ & 0.037 & 0.015 & Beta & (7) \\
\hline $\begin{array}{l}\text { Probability of relapse after } \\
\text { potentially curative RT being } \\
\text { treated with bendamustine- } \\
\text { rituximab (vs. watchful } \\
\text { waiting) }\end{array}$ & 0.24 & 0.043 & Beta & (15) \\
\hline $\begin{array}{l}\text { Probability of progression } \\
\text { requiring bendamustine- } \\
\text { rituximab after non-curative } \\
\text { RT or rituximab induction in } \\
\text { early-stage patients }\end{array}$ & 0.029 & 0.015 & Beta & $(16)$ \\
\hline $\begin{array}{l}\text { Probability of progression } \\
\text { after rituximab induction in } \\
\text { advanced-stage patients }\end{array}$ & 0.035 & 0.023 & Beta & $(18)$ \\
\hline
\end{tabular}




\begin{tabular}{|c|c|c|c|c|}
\hline $\begin{array}{l}\text { Probability of progression } \\
\text { after watchful waiting or non- } \\
\text { curative RT in advanced- } \\
\text { stage patients }\end{array}$ & 0.104 & 0.037 & Beta & $(17,18)$ \\
\hline $\begin{array}{l}\text { Probability of response to } \\
\text { bendamustine-rituximab } \\
\text { after no previous rituximab } \\
\text { induction }\end{array}$ & 0.93 & 0.016 & Beta & (19) \\
\hline $\begin{array}{l}\text { Probability of response to } \\
\text { bendamustine-rituximab } \\
\text { after rituximab induction }\end{array}$ & 0.88 & 0.020 & Beta & (19) \\
\hline $\begin{array}{l}\text { Probability of progression } \\
\text { after bendamustine- } \\
\text { rituximab }\end{array}$ & 0.041 & 0.018 & Beta & (19) \\
\hline $\begin{array}{l}\text { Probability of response to } \\
\text { salvage chemotherapy \# } 1\end{array}$ & 0.85 & 0.023 & Beta & $(20)$ \\
\hline $\begin{array}{l}\text { Probability of response to } \\
\text { salvage chemotherapy \#2 }\end{array}$ & 0.65 & 0.031 & Beta & $(20)$ \\
\hline $\begin{array}{l}\text { Probability of response to } \\
\text { salvage chemotherapy \#3 }\end{array}$ & 0.45 & 0.032 & Beta & $(20)$ \\
\hline $\begin{array}{l}\text { Probability of progression } \\
\text { after salvage chemotherapy }\end{array}$ & 0.165 & 0.047 & Beta & $(20)$ \\
\hline $\begin{array}{l}\text { Probability of death from } \\
\text { bendamustine-rituximab }\end{array}$ & 0.0040 & 0.0039 & Beta & (19) \\
\hline $\begin{array}{l}\text { Probability of death from } \\
\text { rituximab maintenance }\end{array}$ & 0.0020 & 0.0020 & Beta & $(19,21)$ \\
\hline $\begin{array}{l}\text { Probability of death from } \\
\text { salvage chemotherapy }\end{array}$ & 0.0040 & 0.0039 & Beta & $(20)$ \\
\hline $\begin{array}{l}\text { Probability of death in } \\
\text { palliation }\end{array}$ & $\begin{array}{l}0.5 \text { for a } \\
\text { maximum of } \\
2 \text { cycles } \\
\end{array}$ & - & Fixed & \\
\hline $\begin{array}{l}\text { Probability of death from } \\
\text { other causes }\end{array}$ & \multicolumn{3}{|c|}{ Age-related mortality } & $(22)$ \\
\hline \multicolumn{5}{|l|}{ Utilities } \\
\hline $\begin{array}{l}\text { Utility during watchful } \\
\text { waiting }\end{array}$ & 0.85 & 0.020 & Beta & $(25,26)$ \\
\hline $\begin{array}{l}\text { Utility during radiation } \\
\text { therapy }\end{array}$ & 0.85 & 0.020 & Beta & $(25-27)$ \\
\hline $\begin{array}{l}\text { Utility during rituximab } \\
\text { induction }\end{array}$ & 0.83 & 0.020 & Beta & $(25,26)$ \\
\hline $\begin{array}{l}\text { Utility during first remission } \\
\text { after radiation therapy or } \\
\text { rituximab induction }\end{array}$ & 0.88 & 0.010 & Beta & $(25,26)$ \\
\hline $\begin{array}{l}\text { Utility during subsequent } \\
\text { remissions or rituximab } \\
\text { maintenance }\end{array}$ & 0.79 & 0.030 & Beta & $(25,26)$ \\
\hline $\begin{array}{l}\text { Utility during bendamustine- } \\
\text { rituximab }\end{array}$ & 0.62 & 0.030 & Beta & $(28)$ \\
\hline Utility during salvage & 0.53 & 0.05 & Beta & $(29)$ \\
\hline
\end{tabular}




\begin{tabular}{|l|l|l|l|l|}
\hline chemotherapy & & & & \\
\hline Utility during palliation & 0.38 & 0.05 & Beta & $(29)$ \\
\hline Utility of death & 0 & - & Fixed & \\
\hline
\end{tabular}

Abbreviations: RT=radiation therapy; PET/CT= positron emission tomography/computed tomography

Supplemental Table 2: Model parameter cost estimates

\begin{tabular}{|c|c|c|c|c|}
\hline Parameter & Mean (CAD\$) & $\begin{array}{l}\text { Standard } \\
\text { deviation }\end{array}$ & Distribution & References \\
\hline $\begin{array}{l}\text { Cost of radiation } \\
\text { therapy }\end{array}$ & 9,196 & 920 & Gamma & $(30)$ \\
\hline Cost of PET/CT & 1,117 & 112 & Gamma & (31) \\
\hline Cost of biopsy & 250 & 25 & Gamma & (31) \\
\hline $\begin{array}{l}\text { Cost of medical } \\
\text { oncology } \\
\text { consultation }\end{array}$ & 157 & 16 & Gamma & (32) \\
\hline $\begin{array}{l}\text { Cost of rituximab } \\
\text { induction }\end{array}$ & 13,517 & 14 & Gamma & $(23,33,34,36)$ \\
\hline Cost of follow-up & 351 & 35 & Gamma & $(32,35,36)$ \\
\hline $\begin{array}{l}\text { Cost of } \\
\text { bendamustine- } \\
\text { rituximab after } \\
\text { rituximab } \\
\text { induction }\end{array}$ & 46,929 & 4693 & Gamma & $\begin{array}{l}(19,23,32,34,36- \\
38)\end{array}$ \\
\hline $\begin{array}{l}\text { Cost of } \\
\text { bendamustine- } \\
\text { rituximab after } \\
\text { watchful waiting } \\
\text { or radiation } \\
\text { therapy }\end{array}$ & 47,083 & 4708 & Gamma & $\begin{array}{l}(19,23,32,34,36- \\
38)\end{array}$ \\
\hline $\begin{array}{l}\text { Cost of rituximab } \\
\text { maintenance }\end{array}$ & 10,236 & 1024 & Gamma & $\begin{array}{l}(23,32,34,36- \\
38)\end{array}$ \\
\hline $\begin{array}{l}\text { Cost of salvage } \\
\text { chemotherapy \#1 }\end{array}$ & 37,839 & 3784 & Gamma & $(33,39)$ \\
\hline $\begin{array}{l}\text { Cost of salvage } \\
\text { chemotherapy \#2 }\end{array}$ & 17,366 & 1737 & Gamma & (39) \\
\hline $\begin{array}{l}\text { Cost of salvage } \\
\text { chemotherapy \#3 }\end{array}$ & 17,366 & 1737 & Gamma & (39) \\
\hline Cost of palliation & 21,918 & 219 & Gamma & $(40)$ \\
\hline Cost of death & 0 & - & Gamma & \\
\hline
\end{tabular}

Abbreviations: PET/CT= positron emission tomography/computed tomography 